MAKALAH

\title{
PERMAINAN BOLA VOLI
}

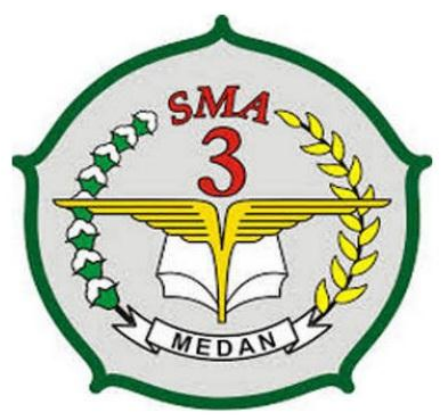

Disusun oleh :

Nama : Amalia Putri Tarigan

Kelas : X Mia 6

SMA NEGERI 3 MEDAN

T.A 2019/2020

Jl. Budi Kemasyarakatan No.3, Pulo Brayan Kota, Kecamatan Medan Barat, Kota Medan, Sumatera Utara 20238 


\section{Kata Pengantar}

Alhamdulillahirabbil'alamin segala puji dan syukur saya panjatkan kepada Allah yanng maha pengasih lagi maha penyayang sehingga saya bisa menyelesaikan tugas makalah yang berjudul Permainan Bola Voli ini tepat pada waktunya

Adapun tujuan dari penulisan dari makalah ini adalah untuk memenuhi tugas guru pada bidang studi Pendidikan Jasmani dan Olahraga Selain itu, makalah ini juga bertujuan untuk menambah wawasan tentang Permainan Bola Voli bagi para pembaca dan juga bagi penulis.

Saya juga mengucapkan terimakasih kepada semua pihak yang telah membagikan sebagian pengetahuannya sehingga saya dapat menyelesaikan tugas makalah ini.

Saya memohon maaf apabila didalam penulisan makalah saya terdapat banyak kesalahan. Semoga makalah yang saya buat ini bisa bermanfaat dan menambah ilmu pengetahuan bagi para pembaca dan penulis tentang bagaimana Permainan Bola Voli. 


\section{BAB I \\ PENDAHULUAN}

\section{A. Latar Belakang}

Permainan bola voli diciptakan oleh William G. Morgan seorang Instruktur pendidikan jasmani (Director of Phsycal Education) di YMCA pada tanggal 9 Februari 1895, di Holyoke, Massachusetts (Amerika Serikat).Beliau dilahirkan di Lockport, New York pada tahun 1870, dan meninggal pada tahun 1942.

YMCA (Young Men's Christian Association) merupakan sebuah organisasi yang didedikasikan untuk mengajarkan ajaran-ajaran pokok umat Kristen kepada para pemuda, seperti yang telah diajarkan oleh Yesus.Organisasi ini didirikan pada tanggal 6 Juni 1884 di London, Inggris oleh George William.Setelah bertemu dengan James Naismith (seorang pencipta olahraga bola basket yang lahir pada tanggal 6 November 1861, dan meninggal pada tanggal 28 November 1939), Morgan menciptakan sebuah olahraga baru yang bernama Mintonette.Sama halnya dengan James Naismith, William G. Morgan juga mendedikasikan hidupnya sebagai seorang instruktur pendidikan jasmani. William G.

Morgan yang juga merupakan lulusan Springfield College of YMCA, menciptakan permainan Mintonette ini empat tahun setelah diciptakannya olahraga permainan basketball oleh James Naismith. Olahraga permainan Mintonette sebenarnya merupakan sebuah permainan yang diciptakan dengan mengkombinasikan beberapa jenis permainan.Tepatnya, permainan Mintonette diciptakan dengan mengadopsi empat macam karakter olahraga permainan menjadi satu, yaitu bola basket, baseball, tenis, dan yang terakhir adalah bola tangan (handball).Pada awalnya, permainan ini diciptakan khusus bagi anggota YMCA yang sudah tidak berusia muda lagi, sehingga permainan ini-pun dibuat tidak seaktif permainan bola basket.

Nama permainan ini semula disebut "Minonette" yang hampir serupa dengan permainan badminton.Jumlah pemain di sini tak terbatas sesuai dengan tujuan semula yakni untuk mengembangkan kesegaran jasmani para buruh di samping bersenam secara massal.William G. Morgan kemudian melanjutkan idenya untuk mengembangkan permainan tersebut agar mencapai cabang olah raga yang dipertandingkan.

Nama permainan kemudian menjadi "volley ball yang artinya kurang lebih mem-volibola pada pada tahun 1896, pada demonstrasi pertandingan pertamanya di International YMCA Training School. Pada awal tahun 1896 tersebut, Dr. Luther Halsey Gulick (Director of the Professional Physical Education Training School sekaligus sebagai Executive Director of Department of Physical Education of the International Committee of YMCA) mengundang 
dan meminta Morgan untuk mendemonstrasikan permainan baru yang telah ia ciptakan di stadion kampus yang baru. Pada sebuah konferensi yang bertempat di kampus YMCA, Springfield tersebut juga dihadiri oleh seluruh instruktur pendidikan jasmani.

Dalam kesempatan tersebut, Morgan membawa dua tim yang pada masing-masing tim beranggotakan lima orang. Dalam kesempatan itu, Morgan juga menjelaskan bahwa permainan tersebut adalah permainan yang dapat dimainkan di dalam maupun di luar ruangan dengan sangat leluasa.Dan menurut penjelasannya pada saat itu, permainan ini dapat juga dimainkan oleh banyak pemain.Tidak ada batasan jumlah pemain yang menjadi standar dalam permainan tersebut. Sedangkan sasaran dari permainan ini adalah mempertahankan bola agar tetap bergerak melewati net yang tinggi, dari satu wilayah ke wilayah lain (wilayah lawan).

Tahun 1922 YMCA berhasil mengadakan kejuaraan nasional bola voli di Negara Amerika Serikat. Pada saat perang dunia I tentara-tenatra sekutu menyebarluaskan permainan ini ke Negara -negara Asia dan Eropa terutama negarea Jepang, Cina, India, Filipina, Perancis, Rusia, Estonia, Latvia, Ceko-slovakia, Rumania, Yugoslavia dan Jerman.

Dalam perang dunia II permainan ini tersebar luas di seluruh dunia terutama di Eropa dan Asia.Setelah perang dunia II prestasi dan popularitas bola voli di USA menurun, sedang di Negara lain terutama Eropa Timur dan Asia berkembang sangat cepat dan massal.

Mengingat turnamen bola voli yang pertama (1947) di Polandia pesertanya cukup banyak, maka pada tahun 1948 I.V.B.F (international volley ball federation) didirikan yang beranggota 15 negara.

\section{B. Rumusan Masalah}

Adanya permainan bola voli yang sering dimainkan maka menimbulkan pertanyaan diantaranya :
A. Sejarah bola voli di Indonesia?
B. Apa peraturan dalam permainan bola voli ?
C. Apa teknik dasar dalam permainan bola voli ?
C. Tujuan
Tujuan penyusunan makalah ini adalah :
A. Untuk mengetahui sejarah bola voli di Indonesia
B. Untuk mengetahui peraturan dalam permainan bola voli
C. Untuk mengetahui teknik dasar permainan bola voli 


\section{BAB II \\ PEMBAHASAN}

\section{A. Sejarah Bola Voli di Indonesia}

Sejarah bola voli ini tidak terlepas dari bagaimana sejarah hidup William G Morgan yang pada akhirnya menciptakan permainan tersebut hingga akhirnya bisa dikenali oleh seluruh dunia. Termasuk di Indonesia. permainan bola voli ini diperkenalkan ke Indonesia pertama kali pada tahun 1928 pada masa penjajahan Belanda.

Pada saat itu, permainan bola voli hanya bisa dimainkan oleh para petinggi besar orang-orang Belanda dan para bangsawan. Hingga akhirnya demi mengembangkan olahraga jasmani di Indonesia, Indonesia mulai belajar berbagai macam ilmu pendidikan jasmani dari orang Belanda.

Sejak dikenalkannya permainan bola voli ini, permainan ini sering dimainkan oleh para tentara di asrama mereka atau di lapangan terbuka. Bahkan terkadang dilakukan pula pertandingan antar regu. Karena olahraga yang satu ini sangat menarik, tidak mengherankan jika banyak yang menyukainya.

Hingga akhirnya olahraga bola voli ini berkembang sangat pesat. Hal ini ditandai dengan munculnya perkumpulan bola voli di kota-kota besar di Indonesia dan didirikannya Persatuan Bola Voli Seluruh Indonesia atau PBVSI pada tahun 1955 tanggal 22 januari.

Pada saat yang bersamaan itulah dilakukan pertandingan bola voli untuk yang pertama kalinya di Indonesia. hingga akhirnya sejarah bola voli bisa berkembang pesat hingga ke pelosok negeri dan bisa dimainkan oleh semua orang seperti sekarang ini.

\section{B. Peraturan Dalam Permainan Bola Voli}

\section{Lapangan Bola Voli}

Untuk persoalan lapangan pada permainan bola voly yaitu berbentuk empat persegi panjang dengan ukurannya adalah Lebar $9 \mathrm{~m}$, panjang $18 \mathrm{~m}$, lebar garis $5 \mathrm{~cm}$. 


\section{Jaring Net}

- Panjang : 9,5 meter

- Lebar : 1,00 meter

- Lebar mata jaring : 10 centimeter

Pada bagian atas net harus ada pita putih yang lebarnya 5 centimeter

- $\quad$ Tinggi jarring net pada voli putra : 2,43 meter

- Tinggi net pada voli puti : 2, 24 meter

Pada kedua tepi net harus dipasang antena yang letaknya lurus di atas garis lapangan.

Warna antena harus belang kontras putih hitam misalnya. Panjang antenna 1,80 meter. Antena terbuat dari bahan yang elastis dengan diameter 1 centimeter.

\section{Kriteria Bola}

- Diameter bola voly : $65 \mathrm{~cm}-67 \mathrm{~cm}$

- Berat : $250-280$ gram

- Tekanan udara : $0,48 \mathrm{~kg} / \mathrm{cm} 2-0,52 \mathrm{~kg} / \mathrm{cm} 2$

- Jumlah jalur : 12 - 18 jalur

Bola voly berbahan kulit yang lunak atau bahan lain yang sejenis, bentuk bola harus bola sempurna dan bahan dalamnya yang terbuat dari karet. Warna bola haruslah terang misalnya warna putih.

\section{Kelengkapan pemain}

Pemain bola voly hendaknya harus mengenakan pakaian olahraga dengan nomor punggung dan dada, memakai celana pendek dan memakai sepatu olahraga.

\section{Jumlah pemain bola voli}

Jumlah pemain dalam satu tim atau regu pada bola voly berjumlah 6 orang dengan banyak pemain cadangan juga enam orang.

\section{Pergeseran pemainan}


Dalam permainan bola voly pergeseran area pemainnya harus searah jarum jam. Bila salah satu regu penerima servis memenangkan permainan, maka semua pemain diberi hak untuk berpindah posisi caranya bergeser kearah jarum jam.

Misalnya posisi tiga melakukan servis, maka posisi 1 bergeser ke posisi 2 .

\section{Waktu Permainan Bola Voli}

Waktu permainan bola voly berdasarkan oleh jumlah poin dalam sebuah set. Dalam sistem rally poin ini jumlah point yang harus di dapat adalah 15 point. Kecuali bila terjadi deuce yaitu 14:14, mungkin atau 24-24.

Untuk memenangkan satu pertandingan bola voly dapat Dua set langsung kemenangan dan Tiga set langsung kemenangan

\section{Pemimpin pertandingan bola voli}

Seorang wasit memimpin jalannya pertandingan dan empat orang penjaga garis dan satu orang sebagai pencatat skor.

\section{Peraturan Teknis Permainan Bola Voli}

Setiap regu di beri hak memainkan bola sebanyak-banyaknya 3 kali.

Seorang pemain tidak boleh memainkan bola lebih dari satu kali secara berturut-turut Regu yang melakukan servis jika memenangkan permainan berhak mendapat satu tambahan poin.

Sebaliknya, apabila tidak dapat mengembalikan bola maka poin untuk lawan.

Bola hidup berati mulai dipukulnya servis ball sampai bola menyentuh tanah.

Ketika servis bola harus dilambungkan lebih baik terlebih dahulu. Bola dinyatakan masuk jika bola jatuh dalam daerah garis lapangan atau bola jatuh tepat pada garis lapangan. 


\section{Sistem libero}

Merupakan suatu sistem pada permainan dimana setiap bola pertama diwakili oleh pemain yang diyakini dapat menjadi libero.

\section{Pelanggaran dalam permainan bola voli}

- Pemain dengan sengaja atau tidak sengaja menyentuh jarring net dengan tangan.

- Pemain tidak dinyatakan pelanggaran jika anggota tubuhnya selain tangan menyentuh net dengan tidak disengaja. Misalnya waktu blocking dadaatau punggung menyentuh net secara tidak sengaja.

- Kedua kaki masuk kedalam daerah lawan.

- Pada pemain yang blocking kedua tangan atau salah satu tangan terlalu masuk ke daerah area lawan.

- Berbicara kasar atau mengumpat terhadap wasit atau juri.

- Menegur wasit dan pembantu wasit.

- Menerima petunjuk dan arahan dari luar lapangan selama pertandingan.

- Pemain mempengaruhi wasit.

- Meninggalkan lapangan pemain tidak izin.

\section{Teknik Dasar Permainan Bola Voli}

\section{Teknik dasar servis bola voli.}

Teknik dasar bola voli yang harus dikuasai pertama kali adalah servis (service). Servis adalah penyajian bola voli pertama dalam bermain bola voli. Hal yang perlu diperhatikan dalam servis adalah sikap badan dan pandangan, lambungan bola, dan timing yang tepat saat memukul bola.

Servis yang merupakan teknik dasar juga dibedakan menjadi 2 yaitu servis atas dan servis bawah. Servis atas dibedakan lagi menjadi tennis service, floating service, dan cekis.

\section{a. Cara melakukan service bawah.}

- $\quad$ Pertama pemain berdiri di kotak servis dengan posisi kaki kiri lebih maju daripada kaki kanan.

- $\quad$ Bola di pegang menggunakan tangan kiri

- $\quad$ Bola dilambungkan tidak telalu tinggi dan tangan kanan ditarik ke belakang bawah 
- $\quad$ Setelah bola setinggi pinggan, tangan kanan diayunkan dan diluruskan ke depan untuk memukul bola

- Tangan ditegangkan dengan posisi telapak tengan kedepan untuk mendapatkan pantulan yang maksimal, tangan juga bisa menggenggam atau terbuka

\section{b. Cara melakukan teknik service atas}

Seperti yang saya jelaskan tadi kalau service dibagi menjadi tennis service, floating service, dan cekis. Tapi kali ini saya akan menjelaskan bagaimana cara melakukan teknik servis atas dengan tennis servis.

- $\quad$ Sikap pertama adalah posisi kaki kiri lebih kedepan daripada kaki kanan dan lutut merendah

- Bola di pegang menggunakan kedua tangan dengan posisi tangan kiri menyangga bola dan tangan kanan diatas bola

- Lambungkan bola keatas menggunkan tangan kanan sampai kira-kira setengah meter diatas kepala

- $\quad$ Kemudian tangan ditarik kebelakang atas hingga dibelakang kepala

- $\quad$ Lakukan gerakan memukul bola dengan pandangan fokus ke bola

- $\quad$ Lecutan tangan dilakukan saat tangan mengenai bola

\section{Teknik passing bawah bola voli}

Yang dimaksud passing dalam bola voli adalah upaya yang dilakukan oleh pemain untuk mengoperkan bola ke taman se tim nya menggunakan teknik tertentu. Teknik passing dalam bola voli sangat penting dalam penyusunan serangan terhadap tim lawan.

Berikut cara melakukan passing bawah

- $\quad$ Berdiri dengan posisi kaki terbuka selebar bahu dan lutut ditekuk

- $\quad$ Rapatkan kedua tangan dan luruskan hingga kedua jempol sejajar

- $\quad$ Ayunkan kedua tangan secara bersamaan dari bawah keatas hingga setinggi bahu

- $\quad$ Lutut diluruskan saat bola mengenai kedua lengan tangan

- Usahakan bola terkena lengan diatas pergelangan tangan

\section{Teknik passing atas dalam permainan bola voli}

Selain passing bawah ada juga passing atas. Berikut cara melakukan passing atas. 
- $\quad$ Posisi awal seperti biasa, yaitu kedua kaki dibuka selebar bahu, lutut agak ditekuk, badan sedikit bungkuk kedepan, dan berat badan bertumpuh pada ujung kaki.

- Disaat bola datang tempatkan badan dibawah bola dengan tangan diangkat dan siku agak ditekuk. Telapak tangan terbuka lebar. Kedua jempol dan telunjuk yang berdekatan membentuk setengah lingkaran atau segitiga

- Disaat bola sampai tepat diatas dari badan tangan ditekuk pada bagian siku dan pergelangan tangan. Posisi tangan berada sedikit diatas dahi. Saat bola jatuh tepat pada jarijari tangan, jari ditegangkan kemudian didorong menggunakan pergerakan kedua tangan dan dibantu dengan meluruskan siku. Hal yang mempengaruhi pendorongan bola adalah ibu jari, telunjuk, dan jari tengah.

- Kemudian gerakan diakhiri dengan tit sedikit terangkat, pinggul dan lutut dinaikkan, kedua lengan lurus dan pandangan mengikuti arah gerakan bola

\section{Teknik Smash dalam bermain bola voli}

Teknik smash adalah teknik serangan yang dilakukan dengan memukul bola secara keras dan melompat yang diarahkan ke daerah lawan yang kosong. Teknik smash merupakan teknik yang harus dikuasai oleh pemain khususnya spiker/penyerang. Teknik smash biasanya dilakukan pada pukulan ketiga setelah pertama yang dilakukan dengan passing bawah, kedua pass ing atas dan diakhiri dengan smash.

Cara melakukan teknik smash bola voli_di bagi 4 bagian yaitu awalan, tolakan, pukulan bola, dan saat mendarat.

\section{Awalan}

- $\quad$ Posisi badan berada dengan jarak 2,5 sampai 4 meter dari net

- Tubuh rilek dan agak condong kedepan

- $\quad$ Berat tubuh diseimbangkan dengan kedua kaki.

\section{Tolakan}

- Jari kaki dan tumit menghentak tanah atau lantai

- Kedua lengan diayunkan kearah depan

- $\quad$ Telapak kaki, pinggul, dan badan digerakkan dengan serasi

- $\quad$ Lakukan lompatan vertkal dan gerakan eksplosif

- $\quad$ Pukulan bola

- $\quad$ Bola berada di depan atas dengan jangkauan lengan pemukul 
- Lecutkan tangan dengan cepat dan pukul bola secepat mungkin dan setinggi mungkin

- $\quad$ Perkenaan bola dengan telapak tangan berada diatas bola

- $\quad$ Setelah memukul bola dilanjutkan lengan melakukan gerakan lanjutan ke arah garis tengah badan

- $\quad$ Pukulan yang benar akan menghasilkan bola yang cepat dan top spin

\section{Sikap mendarat}

- $\quad$ Setelah memukul kembalikan posisi tubuh ke semula dengan sikap sempurna

- $\quad$ Tubuh tetap rilek dan siap dengan serangan berikutnya

- Mendarat dengan kedua kaki mengeper

- $\quad$ Mendarat dengan lutut dan jari-jari kaki lentur

\section{Teknik Block/menghadang bola voli}

Teknik Block adalah teknik yang dilakukan untuk membendung serangan yang dilakukan lawan bola agar tidak melewati net dan tetap di area lawan. Teknik ini juga harus dikuasai oleh setiap pemain untuk mengungguli permainan lawan. Berikut cara melakukan block

- $\quad$ Pemain berada di dekat net dangan melakukan gerakan ke kanan dan ke kiri guna memdekati lawan yang melakukan serangan

- $\quad$ Bersikap siap melakukan bloking yaitu posisi jongkok yang siap melompat dan tangan di depan dada yang siap membendung

- $\quad$ Pemain melompat kearah atas dengan posisi rapat dan lurus keatas untuk membendung bola

- $\quad$ Kemudian mendarat dengan kedua kaki secara lentur 


\section{BAB III \\ PENUTUP}

\section{A, Kesimpulan}

Dalam pemainan dan olahraga bola voli dapat membuat tubuh menjadi sehat karena mengeluarkan keringat dari tubuh.Bola voli juga dapat mehilangkan atau menghidari kejenuhan siswa / siswi dalam mempelajari teknik dasar pemain bola voli.Karena, pemainan dan olahraga bola voli mempunyai peraturan yang dimodifikasi yang membuat siswa / siswi dapat mehilangkan atau menghindari kejenuhan ketika belajar atau memainkan permainan atau olahraga bola voli ini.

\section{B. Saran}

Dalam rangka memainkan permainan bola voli ini, permainan ini dapat dilakukan dengan cara membuat lapangan kecil dengan teknik passing bawah dan cara servis tangan bawah dan hendaklah dalam permainan atau olahraga bola voli ini ditekankan penggunaan teknik yang benar dan terarah sehingga bisa lebih meningkatkan penguasaan teknik nya dalam permainan bola voli itu sendiri. Dan bagi orang yang kelebih lemak, mungkin dengan memainkan permainan bola voli ini bisa membakar lemak karena hasil pembakaran yaitu dengan mengeluarkan keringat bias sedikit demi sedikit membuat kita mempunyai tubuh yang ideal. 


\section{DAFTAR PUSTAKA}

http://junsatu.blogspot.com/2017/12/makalah-voli-lengkap.html

https://moondoggiesmusic.com/sejarah-bola-voli/

https://olahraga.pro/peraturan-permainan-bola-voli/

http://bangunbadan.blogspot.com/2017/11/5-teknik-dasar-bermain-bola-voli.html 